NOTICE: this is the author's version of a work that was accepted for publication in Journal of Petroleum Science and Engineering. Changes resulting from the publishing process, such as peer review, editing, corrections, structural formatting, and other quality control mechanisms may not be reflected in this document. Changes may have been made to this work since it was submitted for publication. A definitive version was subsequently published in Journal of Petroleum Science and Engineering, Vol. 88-89 (2012).

DOI: 10.1016/j.petrol.2011.12.014 


\title{
Tight Gas Sands Permeability Estimation from Mercury Injection Capillary Pressure and Nuclear Magnetic Resonance Data
}

\author{
Reza Rezaee ${ }^{\star 1}$, Ali Saeedi ${ }^{1}$ and Ben Clennell ${ }^{2}$ \\ 1- Department of Petroleum Engineering, Curtin University \\ 2- The Commonwealth Scientific and Industrial Research Organisation (CSIRO) \\ Email: r.rezaee@curtin.edu.au
}

\section{Abstract}

There are several methods to estimate permeability from pore throat sizes and NMR $\mathrm{T}_{2}$ relaxation time. Although most of the methods are well-established and work well for conventional reservoirs they fail to estimate permeability for tight gas sands. The aim of this study was to establish relationships between permeability and pore throat sizes, derived from mercury injection analysis, and $\mathrm{NMR}_{2}$ relaxation time.

Regression analysis was used to achieve a set of relationships between dry gas permeability, porosity and pore throat sizes for 50 tight gas sand samples. Unlike for normal sandstone, pore throat radii corresponding to a mercury saturation of $10 \%$ $\left(r_{10}\right)$ is the best permeability predictor for tight gas sands.

For tight gas sands, NMR $\mathrm{T}_{2}$ relaxation spectra fall on the shorter values corresponding to the smaller pores. This is because pore spaces are significantly reduced both in size and volume due to extensive compaction and cementation. This study shows that using NMR $\mathrm{T}_{2 \text { peak }}$ and multi-regression analysis, permeability can be estimated with high accuracy even in rocks with substantially constricted pore throats.

Keywords: permeability estimation, tight gas sands, mercury injection capillary pressure, NMR relaxation time. 


\section{Introduction}

Based on the in-situ permeability values, reservoirs can be divided into conventional reservoir (permeability more than $1 \mathrm{mD}$ ), near tight (permeability between 1 and 0.1 $\mathrm{mD}$ ), and tight reservoirs (permeability less the $0.1 \mathrm{mD}$ ) (Figure 1). In general tight gas sand is defined as a low permeability gas reservoir that needs specific treatments such as advanced drilling technology, correct way of completion and stimulation jobs to produce gas in commercial scale. For conventional reservoirs, porosity is high and pores are fully connected, whereas on the other hand for near tight and tight rocks pores are occluded and there are fewer connections between the pores. Figure 2 shows the size of pore connections for the conventional sands, tight gas sands and shales. It can be seen that for tight gas sands the typical size of pore throat may become less than 0.1 micron.

Permeability which is a measure of the capacity of a reservoir to deliver hydrocarbons, is one of the most important parameters in reservoir studies. Variation of permeability is related to a series of factors, and there have been many efforts to establish a relationship between these factors and permeability. Permeability is a key parameter in determining the economic value of a hydrocarbon accumulation. It is a complex interplay of porosity, pore connectivity, grain packing, grain size and rock diagenesis.

Generally the magnitude of permeability in a normal sandstone is controlled by the processes active in depositional environment. Therefore rock texture may yield some information about permeability and porosity. Usually for a normal sandstone, diagenesis has small effect on petrophysical properties of the rocks and it is possible to predict the reservoir quality based on sedimentary environment. Tight gas sands, 
on the other hand, present a picture of extremes. Matrix permeability is very low due to extensive compaction and cement precipitation. Techniques that succeed in evaluating the normal sandstones may fail in tight formations.

\subsection{Permeability from Mercury Injection Capillary Pressure (MICP)}

Capillary pressure is the pressure difference existing across the interface separating two immiscible fluids. It critically affects reservoir initial fluid distribution and hydrocarbon recovery during primary or enhanced production. The distribution of multiple fluids in reservoir pores is a function of capillary forces, which in turn are related to system wettability, fluid density and pore geometry. Capillary pressures data have, in the past, been used primarily to evaluate reservoir rock quality, calculate the height of oil columns or estimate relative permeability characteristics. Today, capillary pressure measurements have widespread applications. One of the most important and frequently cited applications is to derive absolute permeability from some attributes extracted from MICP curves (e.g. Purcell, 1949; Calhoun, et al., 1949; Burdine et al., 1950; Wyllie \& Spangler, 1952; Thomeer, 1960; Swanson, 1981; Wells \& Amaefule, 1985; Pittman, 1992; Rezaee, 2006).

A mercury injection curve is a curve which represents the increasing saturation of mercury as a function of pressure. Mercury injection curves can indicate the amount of porosity existing behind pore throats of various sizes (Purcell, 1949). As the mercury is a non-wetting phase, it must be forced to enter the pores of the samples. Pores with the largest throats will be the first penetrated by mercury under increasing pressures. Pores connected with the smallest throats are the last parts of the effective porosity that may be invaded and filled with mercury at the relatively highest pressures. As the reservoir properties such as porosity and permeability are 
controlled by the size and arrangement of pores and throats (McCreesh et al., 1991), mercury injection method is commonly employed to characterise pore-size distribution in rocks.

In addition to dependency of capillary pressure on reservoir properties, numerous researchers have emphasized that the shape of the capillary pressure curve may be primarily affected by the pore geometry (e.g. Rose \& Bruce, 1949). These authors suggest that MICP curves, that reflect capillary pressure of a reservoir rock, are suitable representatives for quantification of pore geometry and incorporation of dynamic data into reservoir models.

Washburn (1921) was one of the pioneers who expressed the relationship between capillary pressures and pore throat radii as:

$$
P_{C}=-2 \gamma \cos \theta / r_{C}
$$

where $P_{C}$ is capillary pressure (psi), $\gamma$ is mercury surface tension (dynes/cm), $\theta$ is contact angle and $r_{c}$ is the radius of the pore throat (micron) being intruded by mercury.

Purcell (1949) related capillary pressure empirically to air permeability through the graphical integral of the curve of mercury saturation versus reciprocal capillary pressure squared. Swanson (1977) noticed that the complete saturation of effectively interconnected pore spaces with a non-wetting phase (Wood's metal) corresponded to the apex of the hyperbola of a log-log mercury injection capillary pressures curve. Swanson (1981) empirically expressed the relationship between permeability and the hyperbola of the log-log mercury injection capillary pressures curve by the following equation: 


$$
k_{\text {air }}=339\left(S_{H G} / P_{C}\right)_{a p e x}{ }^{1.691}
$$

where $k_{\text {air }}$ is air permeability $(\mathrm{mD}), S_{H G}$ is the mercury saturation (\%) corresponding to the apex of the hyperbola and $P_{C}$ is capillary pressure (psi).

Katz and Thompson $(1986,1987)$ reported the following relationship:

$$
k=1 / 226(I c 2)\left(C_{o} / C_{w}\right)
$$

where $l c$ is the characteristic pore size (e.g. the calculated pore size $(\mathrm{mm})$ for the threshold pressure at which mercury forms a connected pathway through the sample), and $C_{o} / C_{w}$ is the ratio of rock conductivity to the conductivity of the formation water. This approach, however, requires a rock sample, laboratory measurement of the threshold pressure and the measurement of rock and formation water conductivity and assumes zero or negligible surface conductivity.

Winland developed an empirical relationship between porosity, air permeability and throat size corresponding to a mercury saturation of $35 \%\left(r_{35}\right)$. This relationship was published by Kolodzie (1980) as:

$$
\operatorname{Logr}_{35}=0.732+0.588 \log _{\text {air }}-0.864 \log \phi
$$

Pittman (1992) extended Winland's work and introduced a series of equations extracted from the multi-regression analyses of mercury injection, permeability and porosity data for sandstone samples. He pointed out that the following equation yields the best R-squared for permeability, porosity and mercury injection data: 


$$
\log k=-1.221+1.415 \log \phi+1.512 \log _{25}
$$

Rezaee et al., (2006) conducted regression analysis and achieved a set of relationships between permeability, porosity and pore throat size for 144 carbonate samples. They indicated that pore throat radii corresponding to a mercury saturation of $50 \%\left(r_{50}\right)$ is the best permeability predictor for carbonates with complex pore networks:

$$
\log k=-1.160+1.780 \log \phi+0.930 \log r_{50}
$$

In above equations $r_{i}$ is the pore throat corresponding to $i_{\text {th }}$ percentile, $k$ is uncorrected air permeability $(\mathrm{mD})$ and $\phi$ is porosity (\%).

\subsection{Permeability from Nuclear Magnetic Resonance (NMR)}

The ability of NMR to distinguish between bound and free fluids increases the capability of NMR to estimate the formation permeability. Several examples of the application of NMR as a tool for prediction of permeability have been reported in the literature (Chang et al., 1994; Coates et al., 1994; Kleinberg et al., 1996; Howard et al., 1997; Tariq et al., 1997; Flaum et al., 1998; Logan et al., 1998; Castelijns et al., 1999; Epping et al., 1999; Quintero et al., 1999; Sezginer et al., 1999; Glover et al., 2006; Daigle and Dugan, 2009). NMR allows differentiating the clay-bound water volume (CBW), pore sizes as irreducible bulk volume (BVI), and the Free Fluid Index (FFI) (Figure 3). This allows defining effective porosity $\left(\phi_{\mathrm{e}}\right)$, total porosity $\left(\phi_{\mathrm{t}}\right)$, and permeability index (k) (Coates et al. 1999). The cutoff to separate BVI from FFI is considered 33msec for normal sandstone. This cutoff could be well established for 
any lithology by conducting NMR measurements on core plug samples under irreducible water saturation (Swir) condition (Chen et al., 1998).

Pore size in terms of $T_{2}$ relaxation time distribution is the main tool for permeability calculation using NMR data. Two common models to estimate permeability are Coates model or the free-fluid model; (applicable in formations containing water and/or hydrocarbons) and Mean $\mathrm{T}_{2}$ model (applicable in formations containing only water).

In the Coates model, $\mathrm{k}$ is estimated by:

$$
k=\left[\left(\frac{\phi}{C}\right)^{2}\left(\frac{F F I}{B V I}\right)\right]^{2}
$$

where, $\mathrm{k}=$ permeability; $\phi=$ porosity $\mathrm{C}=\mathrm{a}$ constant which is a term that reflects the correlation between the rock's pore throat and pore size and in fact it is a function of pore geometry; $\mathrm{FFI}=$ the free fluid index, and $\mathrm{BVI}=$ the bound volume of irreducible water. Core porosity and permeability should be used to estimate $C$ for the Coates model.

The mean $\mathrm{T}_{2}$ model which is also called SDR model (Schlumberger Doll Research) is expressed as:

$$
k=a T_{2 g m}^{2} \phi^{4}
$$

where $T_{2 g m}$ is the geometric mean of the $T_{2}$ distribution, milliseconds; $\phi=N M R$ total porosity, fraction and "a" is a coefficient that depends on the formation type. "a" has 
to be determined through calibration with core porosity and permeability. "a" is equal to 4 for sandstone, and researchers often disagree on the value of the pre factor "a" for carbonate. Chang et al. (1994) believed that $a=4.75$ should be considered for carbonates, which is close to the value used in sandstones.

Figure 4 illustrates the Coates and the SDR models that use the FFI/BVI ratio and geometric mean of the $T_{2}$ values respectively for permeability estimation.

\section{Results and Discussions}

A total of 16 core plugs from one of the Western Australian tight gas sand fields were analysed for this study. Although all samples are collected from a specific tight gas sand reservoir, but due to the nature of the samples, NMR and MICP tests were carried out on different samples. All of the studied samples are fine- to coarse-grained sandstone and are mainly quartz-rich with sub-dominant components of feldspar and lithic fragments. In general, the sandstone could be classified as arkose to lithicarkose. Illite/smectite, kaolinite, and chlorite are the main clay types. There are several major diagenetic processes that have affected the reservoir quality for the studied tight gas sands. Compaction, chlorite, illite-smectite, kaolinite and carbonate cements are the most significant one.

An AP-608, automated permeameter and porosimeter were used for porosity and permeability measurements. Helium porosity and dry gas permeability of the samples used for NMR test were measured under different confining pressures. For these samples porosity ranges from about $12 \%$ to less than $2 \%$. Porosity reduction with increasing confining pressure is not significant for most of the samples (Figure 5). Permeability ranges from about $0.1 \mathrm{mD}$ to less than $0.001 \mathrm{mD}$ at 5000 psi. Permeability values reduce significantly when confining pressure increases (Figure 
6). One of the main controlling parameter for permeability is the pore throat size which is a very tiny element in the rock. Any reduction in the pore throat size will affect the permeability significantly.

\subsection{Mercury Injection Capillary Pressure Test (MICP)}

MICP tests were conducted on 10 samples to examine their pore throat size distribution. Mercury injection capillary pressures were measured using a Micromeritics Autopore 9200.

A total of 40 MICP data from the Mesaverde tight sand database were also used for this part of the study.

Figures 7 and 8 show mercury injection curves and pore throat distribution. Pore sizes have been classified by Hartmann and Beaumont (1999) as nanopores $(<0.1$ microns), micropores (0.1-0.5 microns), mesopores (0.5-2.5 microns), macropores (2.5-10 microns) and megapores (>10 microns). The dominant pore throat sizes for the studies samples are around 0.1 and 1 microns and fall in micropores and mesopores realm.

Permeability estimated from the Winland, Pittman and Rezaee's equations for the tight gas sand samples show a poor correlation with measured core permeability (Figure 9). To find a better relationship between permeability and pore throat sizes, mercury saturations from $5 \%$ to $80 \%$ were used to evaluate the relationship between permeability, porosity and pore throat radius at each saturation. Multi-regression analysis was carried out to establish various relationships between porosity and pore throat size as and permeability. The approach was to develop empirical equations for calculating permeability from porosity and pore throat radius at several mercury saturation percentiles. Table 1 lists the equations developed from the regression 
analysis and the R-squared between the measured permeability and the permeability calculated from the equations. All of the R-squared values are larger than $70 \%$ for $r_{5}$ to $r_{25}$ but $r_{10}$ yields the highest R-squared, $78.1 \%$. The corresponding equation that uses $r_{10}$ is as follows:

$$
\log k=-1.92+0.949 \log P h i+2.18 \operatorname{logr}_{10}
$$

where $\mathrm{k}$ is the dry gas permeability $(\mathrm{mD})$, Phi is porosity (\%) and $\mathrm{r}_{10}$ is the pore throat size (micron) corresponding to the $10^{\text {th }}$ percentile of mercury saturation on a cumulative mercury injection plot.

It seems that Winland, Pittman and Rezaee's equations overestimate permeability (Figure 9) whereas, on the other hand, permeability estimated from the new equation show relatively a good match with the measured permeability (Figures 10).

\subsection{Nuclear Magnetic Resonance (NMR) analysis}

NMR analysis was conducted on nine core plugs fully saturated with $50,000 \mathrm{KCl}$ brine using a MARAN Ultra Magnetic Resonance Core Analyzer. The samples were kept immersed in the solution under vacuum for $48 \mathrm{hrs}$ and then taken out for pressure-saturation at $3 \mathrm{MPa}$ for another $48 \mathrm{hrs}$. Following that the samples were placed in jars full of brine and transferred into the water bath with the temperature of $40^{\circ} \mathrm{C}$ for a minimum of 1 or 2 hours to prepare them for NMR tests.

NMR analysis confirms major pore size occurring at about 1.0 millisecond (Figure 11). Comparing $T_{2}$ distribution of the tight gas sands with normal sands, it can be seen that larger $\mathrm{T}_{2}$ times are not present due to the lack of the macropores in the tight gas sands. Large pores can contribute to higher permeability values. Instead 
the main $\mathrm{T}_{2}$ appears as a major dominant peak at the shorter $\mathrm{T}_{2}$ times (Figure 11). For most of the samples analysed there are minor peaks or a tail distribution of $\mathrm{T}_{2}$ around 10 to 40 millisecond that are most likely related to the remaining larger pores. Prince et al., (2009) demonstrated that $\mathrm{T}_{2 \text { mode }}$ can represent the most common pore size for tight gas sand and shale and thus could be used for permeability estimation. The current study supports their approach but instead of selecting mode value that cannot be statistically obtained from $\mathrm{T}_{2}$ spectrum, value of the $\mathrm{T}_{2 \text { peak }}$ was selected. $T_{2 p e a k}$ is the value of $T_{2}$ that shows the highest frequency on the spectrum and thus is the dominant pore size in the sample. Using $N M R T_{2}$ dominant peak or $\mathrm{T}_{2 p e a k}$ and multi-regression analysis, permeability can be estimated with high accuracy. Multi-regression analysis resulted in the following equation for permeability estimation using $\mathrm{T}_{2 p e a k}$ and porosity:

$$
k=-0.0461-0.0601 T_{2 p e a k}+4.37 \phi
$$

where $k$ is permeability $(m D), T_{2 p e a k}$ is dominant $T_{2}$ on the $T_{2}$ spectrum (ms), and $\phi$ is porosity (fraction).

Cross plot of measured permeability versus NMR $\mathrm{T}_{2 \text { peak }}$ permeability shows a very close correlation (Figure 12).

The general form of the equation is:

$$
\mathrm{k}=-\mathrm{a}-\mathrm{b} \mathrm{T}_{2 p e a k}+\mathrm{c} \phi
$$

where $a, b$ and $c$ could be extracted from the multi-regression analysis for any tight gas sand formation. 


\section{Conclusions}

This study indicates that for tight gas sands pore throat radius at $10 \%$ mercury saturation $\left(r_{10}\right)$ yields the best correlation with permeability. This suggests that both micropores and mesopores, which fall in such a range, are the main contributing parameters for permeability in tight gas sands.

Winland (Kolodzie 1980) and Pittman (1992) proposed $r_{35}$ and $r_{25}$ respectively as the best permeability estimator for normal sandstones. A possible explanation for this difference of the normal sandstone with the tight sands is the pore network complexity of tight sands compared to normal sandstones. For tight gas sands pore throat radius at $10 \%$ mercury saturation $\left(r_{10}\right)$ range from 0.1 to 1 micron. This is the dominant pore throat radius for the samples studied (Figure 8). For normal sandstone at such mercury saturation pore throat radius must be much larger in size and they cannot be a good representative for controlling permeability. On the other hand, for higher mercury saturation (e.g. 35\%), for tight gas sands pore throat radius fall in nanopores range that seems has a little control on permeability (Table 1).

There are two common models for permeability estimation from NMR spectrum. Coates' model uses BVI and FFI defined by a cutoff that should be obtained by core analysis. The second model uses geometric mean of NMR spectrum to estimate permeability. Multi-regression analysis of the dominant $\mathrm{NMR}_{2}\left(\mathrm{~T}_{2 \text { peak }}\right)$ and porosity resulted in an equation that estimate permeability for very low permeability tight gas sands with high accuracy. 


\section{Acknowledgments}

We would like to express our thanks to the Western Australia Department of Mine and Petroleum, Whicher Range Energy and The University of Kansas Center for Research Inc for permission to use the data and for permission to publish this paper. 


\section{References}

Burdine, N.T., Gournay, L.S., and Reichertz, P.P., 1950. Pore Size Distribution of Petroleum Reservoir Rocks, Trans. AIME, 189, p. 195-204.

Calhoun, J.C., Lewis, M. and Newman, R.C., 1949. Experiments on the Capillary Properties of Porous Solids, Trans., AIME, Vol. 186, p. 189-196.

Castelijns, C., Badry, R., Decoster, E., Hyde, C., 1999. Combining NMR and Formation Tester Data for Optimum Hydrocarbon Typing, Permeability and Producibility Estimation. SPWLA 40th Annual Logging Symposium Transactions, paper GG.

Chang, D., et al., 1994. Effective porosity, producible fluid and permeability in carbonates from NMR logging, paper A, 35th Annual SPWLA Logging Symposium Transactions, 21 p. Later published in 1997 in The Log Analyst, v. 38 , no. 2, p. $60-72$.

Chen, S., G. Ostroff, D.T. Georgi, 1998. Improving Estimation of NMR Log T2cutoff Value with Core NMR and Capillary Pressure Measurements, International Symposium of the Society of Core Analysts, The Hague, The Netherlands, September 14-16, paper 9822.

Coates, G.R., Gardner, J.S., and Miller, D.L., 1994. Applying pulse-echo NMR to shaly sand formation evaluation, paper $B$, in 35th annual logging symposium transactions: Society of Professional Well Log Analysts, 22 p.

Coates, G.R., Xiao, L., Prammer, M.G., 1999. NMR Logging Principles and Applications. Halliburton Energy Services Publication H02308.

Daigle, H., Dugan, B., 2009. Extending NMR data for permeability estimation in finegrained sediments. Marine and Petroleum Geology 26, 1419-1427. 
Epping,W.J., Eggenkamp, I.M., Reid, I., 1999. Added value from NMR measurements to characterize Gas Reservoirs in the U.K. Southern North Sea.

Flaum, C., Kleinberg, R.L., Bedford, J., 1998. Bound water volume, permeability, and residual oil saturation from incomplete magnetic resonance logging data. SPWLA 39th Logging Symposium Transactions, Paper UU.

Glover, P.W.J., Zadjali, I.I., Frew ,K.A., 2006. Permeability prediction from MICP and NMR data using an electrokinetic approach. Geophysics 71, 4, 49-60.

Hartmann, D. J., and E. A. Beaumont, 1999, Predicting reservoir system quality and performance, in E. A. Beaumont and N. H. Foster, eds., Exploring for oil and gas traps: AAPG Treatise of Petroleum Geology, Handbook of Petroleum Geology, p. 9-1-9-154.

Howard, J., Williams, J., Thorpe, D., 1997. Permeability from nuclear magnetic resonance logging in a gas-condensate field. SPWLA 38th Annual Logging Symposium Transactions, paper XX.

Katz, A. J. and Thompson, A. H., 1986. Quantitative prediction of permeability in porous rock, Physical Review, Vol. 34, No. 11, p.8179-8181.

Kleinberg, R.L., 1996. Utility of NMR T2 Distributions, Connection with Capillary Pressure, Clay Effect, and Determination of the Surface Relaxivity Parameter rho2. Magnetic Resonance Imaging, v.14, pp.761-767.

Kolodzie, S. Jr., 1980. Analysis of Pore Throat Size and Use of the Waxman-Smits Equation to Determine OOIP in Spindle Field, Colorado, paper SPE 9382 presented at the 1980 Annual Fall Technical Conference of Society of Petroleum Engineers, Sept. 21-24. 
Logan, W.D., Horkowitz, J.P., Laronga, R., Cromwell, D.W., 1998. Practical Application of NMR Logging in Carbonate Reservoirs. Society of Petroleum Engineers Reservoir Evaluation \& Engineering, October.

McCreesh, C.A., Ehrlich, R. and Crabtree, S.J. 1991. Petrography and reservoir physics 2: relating thin section porosity to capillary pressure, Amer. Assoc. Petrol. Geol. Bull., V. 10, 1563-1578.

Nelson, P.H., 2009. Pore-throat sizes in sandstones, tight sandstones, and shales. AAPG Bulletin, v. 93, p. 329-340.

Pittman, E.D., 1992. Relationship of Porosity and Permeability to Various Parameters Derived from Mercury Injection-Capillary Pressure Curves for Sandstone, AAPG, Vol. 76, No. 2, p. 191-198.

Prince, C.M., D.D. Steele, and C.A. Devier, 2009. Permeability Estimation in Tight Gas Sands and Shales using NMR - A New Interpretive Methodology, Presented at the 9th AAPG ICE Meeting in Rio de Janero, Brazil.

Purcell, W.R., 1949. Capillary Pressures-Their Measurement Using Mercury and the Calculation of Permeability Therefrom, Trans. AIME, Vol. 186, p. 39-48.

Quintero, L., Boyd, A., Schlumberger, A., Gyllensten, El-Wazeer, F., Comparison of Permeability from NMR and Production Analysis in Carbonate Reservoirs.

Rezaee, M.R., Jafari1, A., and Kazemzadeh, E., 2006. Relationships between permeability, porosity and pore throat size in carbonate rocks using regression analysis and neural networks. J. Geophys. Eng. 3 (2006) 370-376.

Rose, W., Bruce, W.A., 1949. Evaluation of Capillary Character in Petroleum Reservoir Rock. Trans. AIME, 186: 127-142. 
Sezginer, A., Minh, C., Heaton, N., Herron, M., Freedman, R., Van Dort, G., 1999. An NMR High-Resolution Permeability Indicator. SPWLA 40th Annual Logging Symposium Transactions, paper NNN.

Swanson, B.F., 1977. Visualizing pores and non-wetting phase in porous rocks Society of Petroleum Engineers Annual Fall Technical Conference, SPE Paper 6857 10p.

Swanson, B.F., 1981. A Simple Correlation between Permeabilities and Mercury Capillary Pressures, JPT, p. 2488-2504.

Tariq, S.M., Denoo, S., Cordes, M., 1997. Permeability estimation from modern NMR logging measurements, experiences and applications in the Rocky Mountain area, Society of Petroleum Engineers Rocky Mountain Regional Meeting/Geological Association Field Conference Proceedings, Society of Petroleum Engineers 38378.

Thomeer, J.H.M., 1960. Introduction of a Pore Geometrical Factor Defined by the Capillary Pressure Curve, Trans., AIME, Vol. 213, p. 354-358.

Washburn E.W., 1921. The Dynamics of Capillary Flow. Physical Review 17 (3): 273.

Wells, J.D. and Amaefule, J.O., 1985. Capillary Pressure and Permeability Relationships in Tight Gas Sands, paper SPE 13879 presented at the 1985 Low Permeability Gas Reservoir held in Denver, CO, May 19-22.

Wyllie, M. R. J., and M.B. Spangler. 1952. Application of Electrical Resistivity Measurements to Problem of Fluid Flow in Porous Media. American Association of Petroleum Geologists Bulletin vol. 36, no. 2:359-403. 